\title{
Rules of Engagement: Implementing Student- Centered Learning in Breast Imaging
}

\section{Sheryl G. Jordan, MD, ${ }^{*}$ Elizabeth C. Deans, MD, Meredith Johnson, MD, Sheila S. Lee MD, Gary L. Beck Dallaghan, PhD}

University of North Carolina School of Medicine, Department of Radiology, Chapel Hill, NC (S.G.J., S.S.L.); UNC Health Care, Department of Radiology, Chapel Hill, NC (E.C.D., M.J.); University of North Carolina School of Medicine, Office of Medical Education, Chapel Hill, NC (G.L.B.D.)

${ }^{*}$ Address correspondence to S.G.J. (e-mail: sheryl_jordan@med.unc.edu)

\begin{abstract}
In response to changing learner needs, our institution launched a new translational curriculum wherein basic sciences and clinical skills were integrated, longitudinal patient care experiences provided, and earlier opportunities in specialty fields introduced to better inform residency program decisions. Medical students taking the breast imaging elective were enrolled in a breast imaging immersive experience designed to meet the School of Medicine's core competencies. In focusing the elective on a narrow range of specialized topics and skills, we labeled this experience the Breast Imaging Boot Camp. Outcome data from March 6, 2017, to April 26, 2019, have been analyzed for this report. The modifications made to the elective include: e-mailing a detailed orientation document to students prior to the start of the rotation; assigning students to diagnostic, procedural, and screening roles; the attendance of students at introductory radiology symposia; students' weekly attendance at institutional multidisciplinary and divisional breast radiologicpathologic correlation conferences; student self-study assignments using faculty-vetted resources; student participation in breast biopsy simulation and small parts ultrasound laboratories; the development of a student-centric radiology educational website; and student-directed publishing of digital case files. Medical student feedback and course analytics indicated superior course evaluation scores reinforced by narrative feedback. In website domain utilization data, the breast file domain is the most viewed subspecialty domain. The Breast Imaging Boot Camp is a successful curriculum. Its novelty lies in both its integrated approach to medical student core competencies and its clinician educators' use of today's student-favored teaching tools.
\end{abstract}

Key words: breast imaging; medical student; education; core competencies; clinician educator; training.

\section{Introduction}

In recent years it has been reported that graduating medical students are not prepared for residency training (1). In response to this, the Association of American Medical Colleges (AAMC) produced medical student competencies and further refined them into the Core Entrustable Professional Activities for Entering Residency (2). These concerns have resulted in medical schools considering how to enhance educational experiences to better prepare students for residency training.
As with many other medical schools, our School of Medicine (SOM) restructured its curriculum in an effort to integrate the basic and clinical sciences. The translational education curriculum (TEC) resulted in a preclinical curriculum (the foundation phase), launched in 2014, spanning three semesters to teach 13 systems-based blocks. Longitudinal patient care experiences were incorporated into the preclinical curriculum. The required 12-month clinical experience thereafter (the application phase) included primary care, surgery, women's health, and psychiatry. The final phase of the curriculum 


\section{Key Messages}

- This successful medical student breast imaging elective adopts an integrated approach to medical student core competencies and clinician educators' use of today's student-favored teaching tools.

- Innovations leverage student-preferred educational tools (eg, e-learning, flipped classroom learning, and simulation learning) and principles of cognitive psychology (eg, spaced repetition and interleaving).

- This model achieves high student satisfaction in the following areas: a positive learning environment, skill set development, and patient care responsibilities.

(the individualization phase) was extended, which meant the Department of Radiology had more medical students on electives.

The SOM patterned key curricular components after the Liaison Committee of Medical Education (LCME) Standards, which stress evaluating students based on core competencies and educational outcome measures $(3,4)$. Six core competencies-patient care and clinical skills, medical knowledge, interpersonal and communication skills, professionalism, lifelong learning, and social and health systems science-were emphasized, with the expectation that all students graduate with these essential skills (4).

To better meet the expectations of the millennial generation of learners, we revised our breast imaging medical student curriculum to be more engaging and self-directed $(5,6)$. We had already made significant changes to the resident curriculum for breast imaging $(7,8)$. Based on the success with the residents' curriculum, the medical student elective was modified. The change involved taking an unstructured, service-oriented elective to a student-centric experience, focusing on a narrow range of specialized topics and skills (commonly referred to as a boot camp) that incorporated self-directed learning, case-based discussions, and defined clinical experiences.

We describe the development of a breast imaging elective curriculum, student performance, and the evaluations of this unique educational experience for medical students.

\section{Transforming the Curriculum}

Used as a means to maximize teaching time and foster team building, boot camp tenets were employed to meet our students' core competency needs. Boot camps in medical education typically consist of didactic lectures, simulation activities, and team building in a concentrated curriculum $(10,11)$.

The first enhancement was to redesign the four-week elective curriculum to fulfill the SOM core competencies (Figure 1). This largely involved mapping activities in the elective to the competencies. Gaps in competency education were rectified by the development of additional learning activities for the medical students.

At the start of each breast imaging block, orientation documents were e-mailed to incoming students. These documents included a description of the imaging protocols for the work-up of common presenting breast complaints, the American College of Radiology (ACR) Breast Imaging Reporting and Data System (BI-RADS) Atlas, and a link to a newly created radiology educational website housing additional resources curated by the breast imaging faculty $(12,13)$. Students were asked what specialty they were pursuing to tailor their learning and involvement in patient care accordingly. A proactive

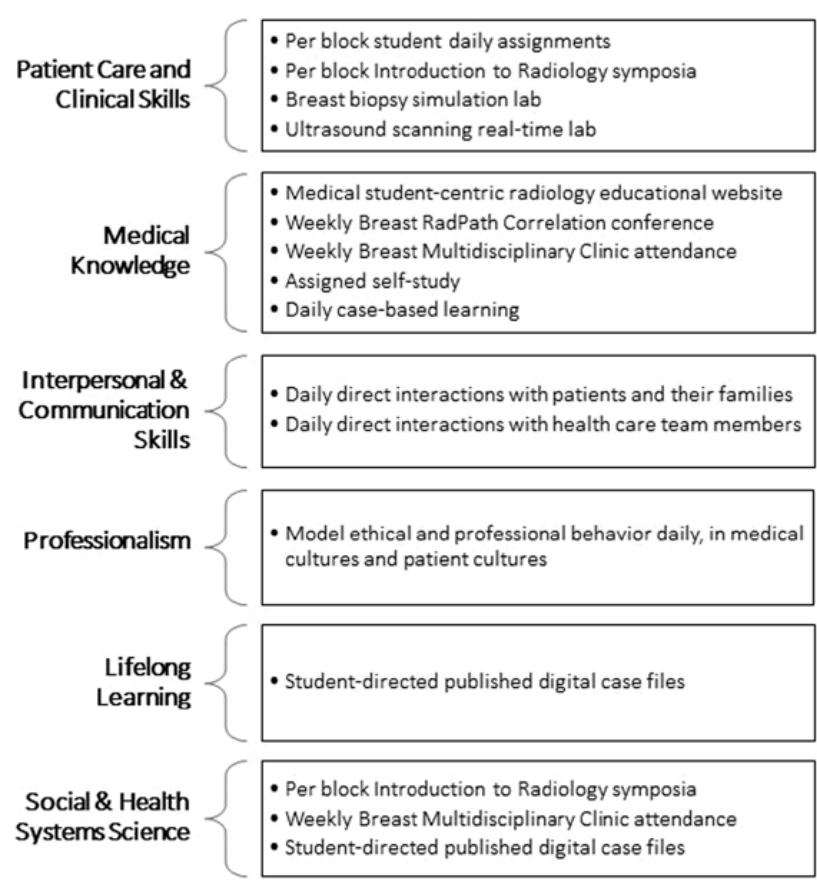

Figure 1. School of Medicine's core competencies and correlative students' Breast Imaging Boot Camp activities.

introduction to the rotation set expectations for an interactive rather than passive experience.

During the four-week block, students rotated among diagnostic, procedural, and screening services for a well-rounded experience. They were required to participate in two four-hour formal Introduction to Radiology didactic symposia as well as weekly radiology-pathology correlation and multidisciplinary breast conferences.

The updated elective included sequential self-study education modules on breast procedures, radiology-pathology correlation, and the management of breast biopsy results followed by live teaching and an emphasis on learned topics at the weekly conferences. The timing of these assignments often preceded their service assignment, employing flipped classroom tenets. Students reviewed teaching files created by peers from prior breast imaging electives. Furthermore, topics encountered in case-based learning were reiterated in follow-up via teaching points sent electronically that evening or the next day, applying principles of interleaving and spaced practice $(14,15)$. New interactive learning components were created, which included a breast biopsy simulation lab and a small parts ultrasound scanning lab.

Students were observed communicating imaging results to patients. Faculty assured graduated procedural and diagnostic responsibilities for the student over the course of the rotation. Typical engaging student activities and skill-set development are shown in Table 1.

\section{Website}

In February 2018, a medical student-centric radiology website was built with limited-access cloud upload capability (available at www.msrads.web.unc.edu). Students had access to the educational content on this open source host site for pre-study, in-clinic education, and post-teaching reference. Using no-cost institutional 
Table 1. Breast Imaging Boot Camp Medical Student Activities and Skill-Set Development

\section{Activity: Direct Patient Care}

Observe patient screening and diagnostic mammography

Observe patient breast ultrasound

Present new diagnostic patient work-ups

Observe patient being given normal and abnormal results

Give patient normal results

\section{Activity: Clinical Skills}

Participate in introduction to radiology symposia (all modalities)

Participate in intradisciplinary radiology pathology conference Attend breast multidisciplinary conference

Develop clinical breast exam skills

\section{Activity: Point of Care Ultrasound}

Observe patient breast and axillary ultrasound

Learn transducer orientation, impact of gain, depth, focal zone

Recognize normal rib and normal fat lobule

Perform selected targeted breast ultrasound (palpable mass in young

patient, palpable mass, cyst vs solid mass, abscess vs mastitis)

Perform selected axillary ultrasound

\section{Activity: Breast Procedural Skills}

Observe ultrasound-guided aspiration and ultrasound-guided core needle biopsy

Observe stereotactic-guided core needle biopsy

Observe MR-guided core needle biopsy

Observe imaging-guided needle localization

Develop sterile technique skills

Perform selected ultrasound-guided procedure steps (cyst

aspiration, needle biopsy)

Perform selected stereotactic-guided core needle biopsy

procedure steps

Perform selected imaging-guided needle localization steps

Activity: Simulation Labs

Participate in point of care ultrasound sim lab

Participate in chicken breast biopsy lab

\section{Activity: Case Presentation}

Review existing peer student case presentation teaching files

Select patient case for new teaching file

web publishing services on a WordPress platform (Automattic, San Francisco, CA) hosted on enterprise-level hardware, the site is supported by the institution's information technology digital services. The website main menu links to the student formal didactic radiology lecture calendar and a custom-built health sciences library page with e-resources for imaging, teaching files, and each radiology course. The breast domain (https://msrads.web.unc.edu/ breast/) is illustrated in Figure 2, showing the faculty-curated educational e-modules spanning breast disease topics, journal reference articles, video shorts, block orientation, digital case files, and the ACR BI-RADS Atlas reference card (12). The educational website ensured consistency within the rotation among students, which is especially crucial when attending faculty schedules change. Website analytics provided by Google Analytics (Google, Mountain View, CA) were analyzed.

\section{Outcomes}

Medical student evaluations of the Breast Imaging Boot Camp from the first two academic years of the curriculum were collected using One45 software (One45, Vancouver, BC). Dates included March 2017 to April 2019. Students rated the rotation on a scale of 1-10 (1 being the worst and 10 being the best). Students also provided narrative comments, which were reviewed to identify frequent statements about their experience. This project was exempted by the institution's Office of Human Research Ethics and Institutional Review Board.

The breast imaging radiology course was rated 10 out of a possible 10 in each of the two TEC academic years, with individual parameters highly scored (Tables 2 and 3 ). Ratings were greater than all other radiology electives. Upon reviewing the narrative comments, students frequently wrote comments similar to this: "I felt included as part of the medical team and was able to actively learn by participating in procedures." They noted, "The educational resources provided by the radiology department were excellent and helped orient me to the rotation tremendously as well as reinforce clinical examples." Students also made suggestions about how to improve the elective, which were incorporated when possible. One such example is the students' desire to present more mammographic results.

The medical student education website analytics showed immediate subscription to the site and 11419 page views over its 15 -month existence during this study. The breast file domain was the most-viewed subspecialty domain, with 916 views, far surpassing other subspecialty pages (Table 4).

\section{Discussion}

Traditionally, medical students take on an observational role during their radiology rotations, peering over the shoulders of the interpreting radiologist and listening to the interpretation as a patient study is dictated. The patient may exist only on a PACS monitor, and patient worklists-rather than an intentional curriculum-may determine what is taught. This sets the stage for possible fragmented learning experiences and curricular gaps for the student.

In an effort to ensure that medical student education in breast imaging addressed all core competencies, we sought to challenge this typical radiology rotation. We offered education that was not only more comprehensive and consistent between students and rotations but also more engaging for the student with hands-on learning. Each student was scheduled on diagnostic, procedure, and screening days in a deliberate manner. A centralized website with high-yield resources equipped students to participate in conferences and establish their presence as a learner on the rotation. More frequent shoulder-to-shoulder teaching and an overall improved rotation experience was emphasized. Finally, emphasis of teamwork and active participation helped to highlight the role of the radiologist as the patient-facing provider and consultant, laying the foundation for future positive multidisciplinary collaboration. This approach was well-received by medical students independent of their chosen specialty.

These course innovations leverage today's learner-preferred educational tools of e-learning, flipped classroom learning, and simulation learning $(5,6,16,17)$. Today's learners use smartphones, digital tablets, computers, and online resources extensively, and adapt readily to learning new technology. The students were continuously 


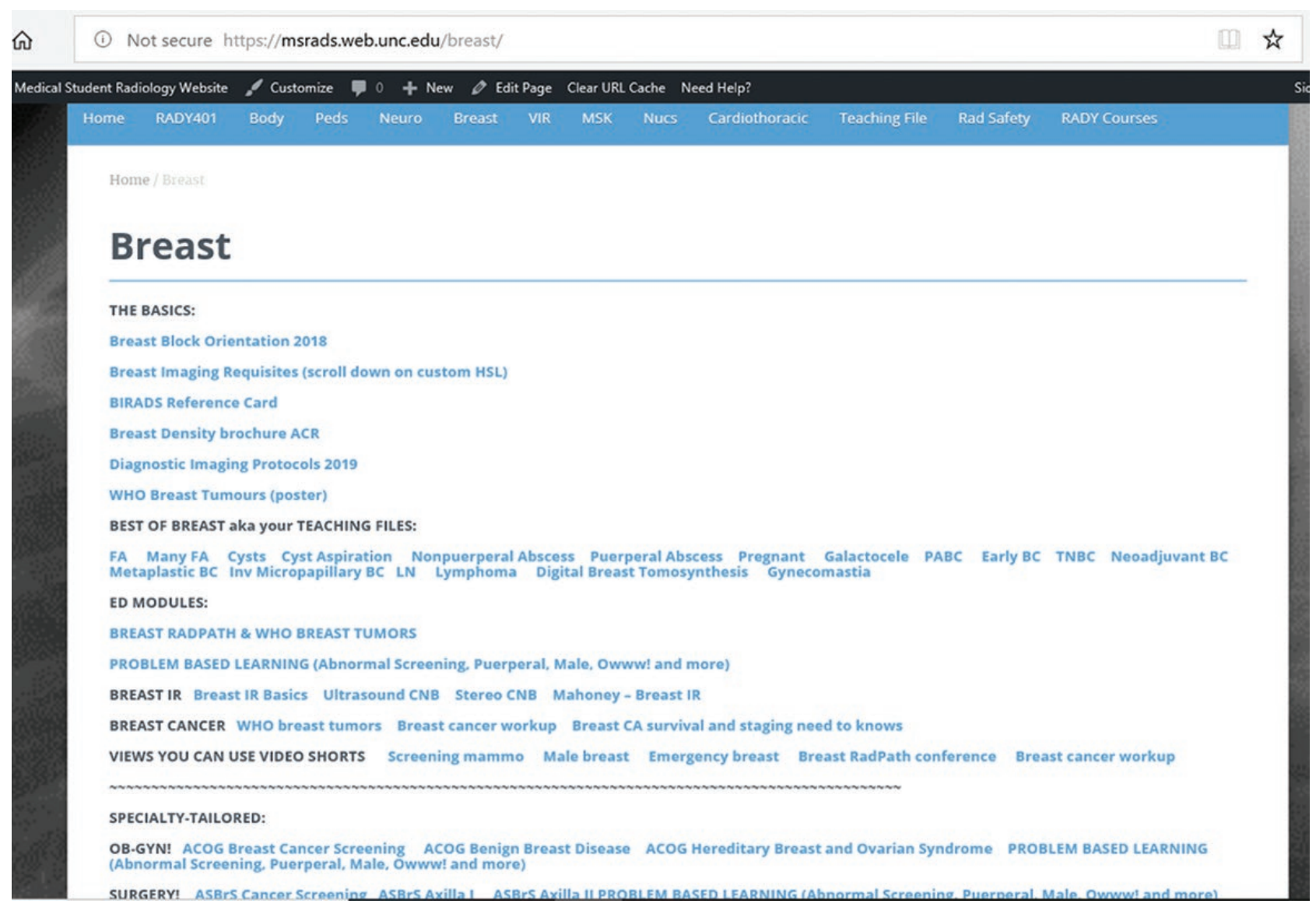

Figure 2. Radiology medical student website.

Table 2. Radiology Course Medical Student Evaluations: Overall Course Rating

\begin{tabular}{lcc}
\hline TEC Radiology Course & 2018-2019 $(\mathbf{n}=\mathbf{1 5 1})$ & $\mathbf{2 0 1 7 - 2 0 1 8}(\mathbf{n}=\mathbf{1 1 3})$ \\
\hline General radiology & $9.1(59)$ & $8.3(55)$ \\
Pediatric radiology & $7.9(10)$ & $9.0(6)$ \\
Neuroradiology & $9.8(8)$ & $8.0(9)$ \\
Vascular interventional radiology & $9.9(9)$ & $9.9(17)$ \\
Bone and joint radiology & $9.0(13)$ & $8.3(4)$ \\
Breast imaging & $10.0(6)$ & $10.0(5)$ \\
Cardiothoracic radiology & $9.6(13)$ & $9.0(10)$ \\
Body imaging & $8.9(33)$ & $9.4(7)$ \\
\hline
\end{tabular}

able to quickly reference the educational resources on the host site while both on and off rotation, with the ability to access the information in a variety of settings. Implementing flipped classroom learning increased the medical students' perception of the amount of knowledge acquired during educational activities; we went further and added recap activities (14-16). The qualitative student and faculty evaluation frequently listed the ease with which the educational content was accessed and reinforced when there was full knowledge of the posted resources.

The elective's point of care ultrasound, in particular, is a considerable motivating factor for medical students (18-20). Not only does it allow for real-time imaging and diagnosis, it also familiarizes students with various presentations of pathology and adds to their diagnostic tool belt (18).
There are a few teaching tips to highlight for the busy clinician educator role many faculty play (21). After two years of experience, lessons learned include: (1) prepping and delivering the simulation labs in a precise, repetitive manner; (2) sending the reiterative e-mails by harvesting teaching points from a document prefilled with teaching points that can be easily excerpted and sent to students; (3) using a template software platform when developing new educational modules; and (4) committing the specific educational module and case files available online to memory. These are four examples that facilitate efficient teaching and effective learning $(21,22)$. Knowing the content on the website well enabled faculty to readily refer the students to a follow-up learning module or article. Also featured on the website are student-selected and student- 
Table 3. Rules of Engagement: Implementing Student-Centered Learning in Breast Imaging

\begin{tabular}{lrr}
\hline & $2018-2019(\mathrm{n}=6)$ & $2017-2018(\mathrm{n}=5)$ \\
\hline This course helped me develop skills in analyzing clinical or research problems. & 10.0 & 9.8 \\
This course helped me develop judgment in addressing patient management issues. & 10.0 & 9.2 \\
The online information for this course was helpful. & 10.0 & 9.6 \\
The site director, faculty, and residents promoted a positive learning environment. & 10.0 & 9.8 \\
How effective was the teaching in the clinical setting by faculty/attendings or preceptors? & 10.0 & 10.0 \\
How effective was the teaching in the clinical setting by residents/fellows? & 10.0 & 9.8 \\
I was given the appropriate level of responsibility for patient care. & 10.0 \\
\hline
\end{tabular}

Table 4. Radiology Medical Student Educational Website Feb 4, 2018-Apr 26, 2019

\begin{tabular}{lc}
\hline Page & Page Views \\
\hline Home & 4209 \\
General radiology & 2545 \\
Teaching file & 2334 \\
Breast & 916 \\
Body & 443 \\
Neuroradiology & 252 \\
Pediatric radiology & 237 \\
Musculoskeletal radiology & 184 \\
Cardiothoracic radiology & 159 \\
Vascular interventional radiology & 140 \\
\hline
\end{tabular}

produced teaching files based on actual patient presentations and imaging findings. Referencing these teaching files as a teaching tool readily engages students $(22,23)$.

This innovative curriculum description is limited in that it is from a single institution. However, the enhancements made to the breast imaging elective can be replicated at other institutions. A future evaluation of this curriculum will be to quantify faculty time preparing or revising modules to determine the true cost of this effort.

\section{Conclusion}

The Breast Imaging Boot Camp is a successful curriculum, readily meeting our learners' needs. Its novelty lies in both its integrated approach to medical student core competencies and its clinician educators' daily use of teaching tools. This structure could be developed at any medical school to provide students with a competency-based education in breast imaging.

\section{Conflict of interest statement}

None declared.

\section{References}

1. Sachdeva AK, Loiacono LA, Amiel GE, Blair PG, Friedman M, Roslyn JJ. Variability in the clinical skills of residents entering training programs in surgery. Surg 1995;118:300-8; discussion 308.

2. Association of American Medical Colleges. Core entrustable activities for entering residency. Available at: https://members.aamc.org/eweb/upload/Core \%20EPA\%20Curriculum\%20Dev\%20Guide.pdf. Accessed 11 August 2018.

3. Liaison Committee on Medical Education. Functions and Structures of a Medical School. Available at: http://lcme.org/publications. Accessed 7 November 2017.
4. UNC School of Medicine Core Competencies. Available at https:// www.med.unc.edu/md/curriculum/files/2018/06/UNCSOM-CoreCompetencies.pdf. Accessed 14 February 2019.

5. Hopkins L, Hampton BS, Abbott JF, et al. To the point: medical education, technology, and the millennial learner. Am J Obstet Gynecol 2018;218:188-192.

6. Scott K, Morris A, Marais B. Medical student use of digital learning resources. Clin Teach 2018;15:29-33.

7. Monticciolo DL, Rebner M, Appleton CM, et al. The ACR/Society of breast imaging resident and fellowship training curriculum for breast imaging, updated. J Am Coll Radiol 2013;10:207-10.e4.

8. Harvey JA, Nicholson BT, Rochman CM, Peppard HR, Pease CS, DeMartini NA. A milestone-based approach to breast imaging instruction for residents. J Am Coll Radiol 2014;11:600-605.

9. Esterl RM Jr, Henzi DL, Cohn SM. Senior medical student "Boot Camp": can result in increased self-confidence before starting surgery internships. Curr Surg 2006;63:264-268.

10. Jambhekar K, Meek ME, Major V, Coker DJ, Deloney LA. Radiology boot camp: facilitating the transition of interns into residents. J Am Coll Radiol 2014;11:329-331.e1.

11. Fernandez GL, Page DW, Coe NP, et al. Boot cAMP: educational outcomes after 4 successive years of preparatory simulation-based training at onset of internship. J Surg Educ 2012;69:242-248.

12. D’Orsi CJ, Sickles EA, Mendelson EB, Morris EA et al. ACR BI-RADS® Atlas, Breast Imaging Reporting and Data System. Reston, VA: American College of Radiology; 2013.

13. Ikeda DM, Miyake KK. Breast Imaging: The Requisites. 3rd ed. St. Louis, Missouri: Elsevier Inc; 2017.

14. Poediger HL, Pyc MA. Inexpensive techniques to improve education: applying cognitive psychology to enhance educational practice. JARMAC 2012;1:242-248.

15. Kang SHK. Spaced repetition promotes efficient and effective learning: policy implications for instruction. Policy Insights Behav Brain Sci 2016;3:12-19.

16. Kerfoot BP, DeWolf WC, Masser BA, Church PA, Federman DD. Spaced education improves the retention of clinical knowledge by medical students: a randomised controlled trial. Med Educ 2007;41:23-31.

17. Ramnanan CJ, Pound LD. Advances in medical education and practice: student perceptions of the flipped classroom. Adv Med Educ Pract 2017;8:63-73.

18. Dietrich CF, Hoffmann B, Abramowicz J, et al. Medical student ultrasound education: a WFUMB position paper, part I. Ultrasound Med Biol 2019;45:271-281.

19. Dietrich CF, Goudie A, Chiorean L, et al. Point of care ultrasound: a WFUMB position paper. Ultrasound Med Biol 2017;43:49-58.

20. Davis JJ, Wessner CE, Potts J, Au AK, Pohl CA, Fields JM. Ultrasonography in undergraduate medical education: a systematic review. J Ultrasound Med 2018;37:2667-2679.

21. Ferenchick G, Simpson D, Blackman J, DaRosa D, Dunnington G. Strategies for efficient and effective teaching in the ambulatory care setting. Acad Med 1997;72:277-280.

22. Richmond A, Cranfield T, Cooper N. Study tips for medical students. BMJ 2019;365:k663.

23. Lilly JF, Verma NV, Jordan SG, Oldan JD, Fordham LA, Noone PG, Beck Dallaghan GL. Medical student imaging case files in the cloud. Clin Teach 2019 Aug 26. doi: 10.1111/tct.13059. [Epub ahead of print] 